\title{
Spatiotemporal effects of logging and fire on tall, wet temperate eucalypt forest birds
}

\author{
David B. Lindenmayer (D) ${ }^{1,2,3}$ Wade Blanchard, ${ }^{1}$ David Blair, ${ }^{1,2}$ Martin J. Westgate, ${ }^{1}$ and Ben C. Scheele ${ }^{1,2}$ \\ ${ }^{1}$ Fenner School of Environment and Society, The Australian National University, Canberra, Australian Capital Territory 2601 \\ Australia \\ ${ }^{2}$ Threatened Species Recovery Hub, National Environmental Science Program, Fenner School of Environment and Society, The \\ Australian National University, Canberra, Australian Capital Territory 2601 Australia
}

Citation: Lindenmayer, D. B., W. Blanchard, D. Blair, M. J. Westgate, and B. C. Scheele. 2019. Spatiotemporal effects of logging and fire on tall, wet temperate eucalypt forest birds. Ecological Applications 29(8): e01999. 10.1002/eap.1999

Abstract. Forests globally are subject to disturbances such as logging and fire that create complex temporal variation in spatial patterns of forest cover and stand age. However, investigations that quantify temporal changes in biodiversity in response to multiple forms of disturbance in space and time are relatively uncommon. Over a 10-yr period, we investigated the response of bird species to spatiotemporal changes in forest cover associated with logging and wildfire in the mountain ash (Eucalyptus regnans) forests of southeastern Australia. Specifically, we examined how bird occurrence changed with shifts in the proportion of area burned or logged in a $4.5 \mathrm{~km}$ radius surrounding our 88 long-term field survey sites, each measuring 1 ha in size. Overall species richness was greatest in older forest patches, but declined as the amount of fire around each site increased. At the individual species level, 31 of the 37 bird species we modeled exhibited a negative response to the amount of fire in the surrounding landscape, while one species responded positively to fire. Only nine species exhibited signs of recovery in the $6 \mathrm{yr}$ of surveys following the fire. Five species were more likely to be detected as the proportion of logged forest surrounding a site increased, suggesting a possible "concentration effect" with displaced birds moving into unlogged areas following harvesting of adjacent areas. We also identified relationships between the coefficients of life history attributes and spatiotemporal changes in forest cover and stand age. Large-bodied birds and migratory species were associated with landscapes subject to large amounts of fire in 2009. There were associations between old growth stands and small-bodied bird species and species that were not insectivores. Our study shows that birds in mountain ash forests are strongly associated with old growth stands and exhibit complex, timedependent, and species-specific responses to landscape disturbance. Despite logging and fire both being high-severity perturbations, no bird species exhibited similar responses to fire and logging in the landscape surrounding our sites. Thus, species responses to one kind of landscapescale disturbance are not readily predictable based on an understanding of the responses to another kind of (albeit superficially similar) disturbance.

Key words: concentration effects; disturbance-congruence hypothesis; eucalypt forests; landscape context effects; mountain ash; southeastern Australia; spatial change in cover.

\section{INTRODUCTION}

Forests are dynamic environments subject to disturbances that can alter stand characteristics, such as stand structural complexity and plant species composition, as well as modify spatial patterns of stand age across a landscape (Lindenmayer and Franklin 2002, Frelich 2005, Ritchie 2010, Pulsford et al. 2016, Thom and Seidl 2016, Seidl et al. 2018). Indeed, disturbance regimes often drive changes in the amount and configuration of suitable habitat in a landscape (Clarke 2008, Clavero

Manuscript received 4 June 2019; accepted 12 July 2019; final version received 28 August 2019.

Corresponding Editor: Carolyn H. Sieg.

${ }^{3}$ E-mail: david.lindenmayer@anu.edu.au et al. 2011, Farnsworth et al. 2014, Kelly et al. 2016), the spatial patterns of abundance of species (Nimmo et al. 2013, Maravalhas and Vasconcelos 2014, Sitters et al. 2014), and the viability of populations of forestdependent taxa (Todd et al. 2016, Taylor et al. 2017). However, quantifying the landscape-scale response of biodiversity to disturbances such as fire and logging is challenging for several reasons. First, unlike many agricultural environments where vegetation disturbance can result in permanent land clearing and transformation to an entirely new ecosystem (Watson et al. 2014, Haddad et al. 2015), forests can regenerate after disturbances such as wildfire and timber harvesting (Lindenmayer and Franklin 2002, Fedrowitz et al. 2014). Thus, activities like logging have important spatiotemporal 
dimensions with cutblocks added to a landscape over time, but these are counterbalanced by the regeneration of previously harvested areas (Franklin and Forman 1987). Second, whereas logging can produce relatively predictable sets of newly disturbed areas over time, wildfires in many forested ecosystems can be rare events that have episodic and often unpredictable impacts on the distribution of stand ages in the landscape (McCarthy and Burgman 1995). Given such complexities, investigations that quantify changes in biodiversity in relation to temporal changes in the spatial patterns of forest cover are relatively uncommon. Limited understanding of the effects on biodiversity from cumulative spatial patterns of cover created by both logging operations and fires is one such knowledge gap (Simon et al. 2002, Slik et al. 2002, Bergeron et al. 2006, Spies et al. 2007, Hart and Chen 2008, Driscoll et al. 2010, Lindenmayer 2016).

In the study reported here, we quantified relationships between temporal patterns of bird detections over a 10yr period and spatiotemporal changes in forest cover. We conducted this study in the mountain ash (Eucalyptus regnans) forests of the Central Highlands of Victoria, Australia (Fig. 1a), where both logging and wildfire create new stands of young forest that are readily distinguished from long undisturbed areas (e.g., those not subject to logging or fire in the past $80 \mathrm{yr}$ ) both on the ground and with remote sensing (Fig. 1b). This makes the mountain ash ecosystem a useful one in which to quantify the effects on biota of spatiotemporal changes in forest cover. Previous studies in mountain ash forests have highlighted site-level differences in the effects of logging vs. the effects of fire on key components of stand structure. These include the abundance of large old trees (Lindenmayer et al. 2016), the abundance of tree ferns and resprouting plant species (Lindenmayer and McCarthy 2002, Blair et al. 2016, Bowd et al. 2018), and levels of soil nutrients and patterns of soil structure (Bowd et al. 2019). Our focus was on relationships between apparent site occupancy as reflected by forest bird detections and spatiotemporal patterns of forest cover generated by (1) logging operations that have taken place in mountain ash forests over the past $63 \mathrm{yr}$ (since 1955) and (2) a major wildfire that occurred in these forests in 2009. We pose three key questions:

\section{Q1. Does the amount of clearcut logging in the landscape influence bird species richness and site occupancy by individual bird species?}

At the outset of this study, we predicted that bird species richness (defined as the number of bird species that we recorded) and detections of individual species would be negatively influenced by increasing amounts of logged forest in the landscape. We made this prediction because clearcut logging results in major changes in stand structure that can be important for forest birds (Blair et al. 2016, Lindenmayer et al. 2016, Bowd et al. 2018).
Q2. Does the amount of wildfire in the landscape influence bird species richness and site occupancy by individual bird species?

Given that wildfires are typically high-severity and high-intensity stand-replacing events in mountain ash forests (Ashton 1981), together with the marked paucity of early successional species in this ecosystem (Lindenmayer et al. 2014), we predicted that large amounts of burned forest in the landscape would depress both bird species richness and levels of site occupancy by individual species. Many forests are characterized by a decline in species diversity following disturbance (e.g., Simon et al. 2002, Kodandapani et al. 2004, Kotliar et al. 2007, Pons and Clavero 2010, Clavero et al. 2011, Phalan et al. 2019), although there are locations, such as some North American forests, that support a suite of early successional species (Hutto 1995, Swanson et al. 2011).

\section{Q3. Are relationships between bird site occupancy and fire and logging predictable based on key life history attributes?}

Species with particular functional traits are prone to decline in landscapes undergoing change (Tylianakis et al. 2008, Lindenmayer et al. 2015), including those subject to fire (Sitters et al. 2016). This is termed the "performance filtering hypothesis" (Mouillot et al. 2012) in which particular functional traits can be "filtered out" by increasing amounts of disturbance in the landscape. In this study, we focused on three traits; body mass, movement patterns, and diet. These traits are important in explaining responses to altered natural disturbance regimes and the impacts of human disturbance, including for birds in other Australian ecosystems (Lindenmayer et al. 2018a, 2019). Body mass is linked to abundance, energy use, and geographic range size (Calder 1984, Schmidt-Nielsen 1984, Lomolino and Perault 2007), and to the risk of species decline across taxonomic groups, with global analyses suggesting that large-bodied vertebrates are at particular risk of decline (Tilman et al. 2017). In Australian woodlands, largebodied birds are declining and small-bodied species are increasing (Lindenmayer et al. 2018b). However, in Europe, small-bodied birds are declining, whereas large species are increasing (Inger et al. 2014). Given that fire and logging often lead to very densely stocked stands of young trees, and that these environments typically provide cover for small-bodied birds but hinder movement by large-bodied birds, we predicted that large body size would be a trait filtered out by increasing amounts of disturbance in the landscape. We also examined whether there were relationships between movement status (migratory vs. resident taxa) and site occupancy. We selected this trait because, worldwide, migratory species are thought to be among the most severely declining taxa, not only due to climate change and extreme weather, but also other factors like habitat loss (Sanderson et al. 


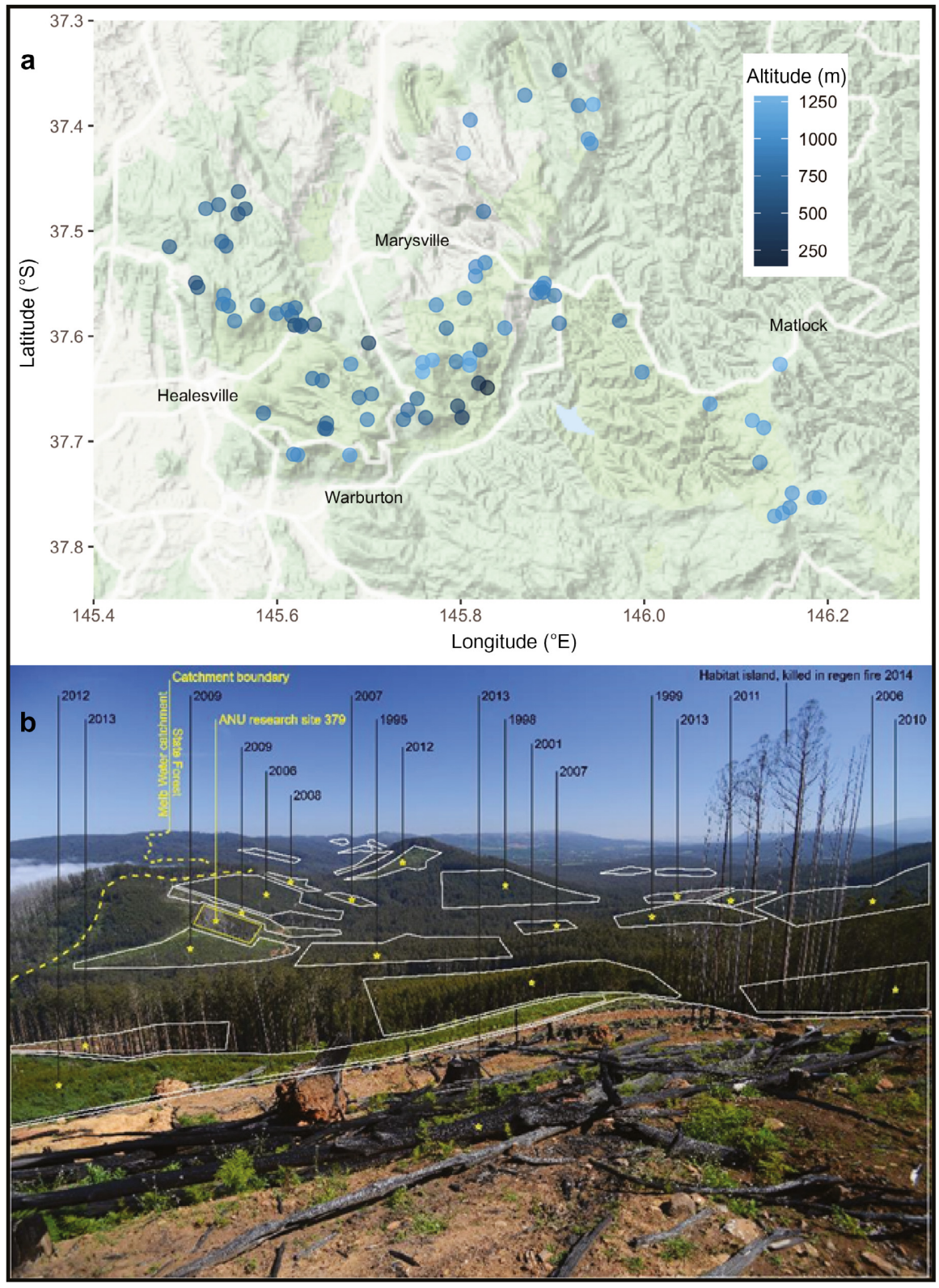

FIG. 1. (a) Map of the study region. The different colored blue dots correspond to sites at different elevation. (b) Spatial and temporal changes in the forest cover resulting from logging in the mountain ash forests in the Central Highlands of Victoria, Australia (photo by David Blair taken in 2014). The stand-replacing nature of fire and logging in mountain ash ecosystems means it is possible to quantify the amount of forest surrounding our long-term sites perturbed in any given year. Our sites (shown as blue dots on the map) spanned a range of landscapes where there has been varying amounts of disturbance by fire and logging (see Appendix S1: Table S2). The photo in panel b shows ANU research site 379 (marked with a yellow line). The white lines correspond to the boundaries of cutblocks logged and the yellow stars show a point within that harvested unit with the corresponding year of cutting. Note that no field sites were logged although the surrounding areas were harvested in many of the landscapes targeted for study.

2006, Both et al. 2010, Runge et al. 2015, Barlein 2016, Gilroy et al. 2016). At the outset of this investigation, we predicted that migratory species would be more severely affected by increasing amounts of disturbance in the landscape than residents, because the strong physiological demands on migratory taxa that result from long distance travel (see Guillemete et al. 2016) could reduce their resilience to increasing amounts of forest perturbation in the landscape. The third trait we examined was diet through comparing insectivores with species that consume other kinds of food. There have been substantial declines of invertebrates in many parts of the 
world (e.g., Powney et al. 2019), and in Australia major changes in insect populations have been associated with some kinds of disturbances, albeit largely in agricultural areas and not forests (Gibb and Cunningham 2010, Barton et al. 2016). Based on potential changes in insect prey in disturbed mountain ash forests (see Pulsford 2012), at the outset of this investigation, we predicted that insectivory would become proportionally less prevalent as a consequence of increasing amounts of disturbance in the landscape.

\section{Methods}

\section{Study region}

Our study region encompassed a $60 \times 80 \mathrm{~km}$ subset of the Central Highlands of Victoria, which is located approximately $60-120 \mathrm{~km}$ northeast of Melbourne, in southeastern Australia (Fig. 1a). We confined our work to forests of mountain ash (Eucalyptus regnans). Mountain ash trees are obligate seeders, meaning that wildfires generally kill trees and the forest regenerates only from seed (Smith et al. 2013), creating even-aged cohorts of trees. The mean fire return interval in mountain ash forests has been estimated at $107 \mathrm{yr}$ (McCarthy et al. 1999), but ranges from 30 to $\geq 300 \mathrm{yr}$ depending on the location within the landscape (Lindenmayer 2009). Clearcutting is the primary form of logging in mountain ash forests (Lutze et al. 1999) and, like fire, creates primarily evenaged cohorts of post-disturbance regeneration.

Our 88 field sites spanned a range of stand age classes (see Table 1). At the commencement of our investigation, we assigned our sites to one of four stand age classes: (1) those that dated from before 1900 (hereafter referred to as "old growth"), (2) regeneration from a wildfire in 1939 but that have not since been burned, (3) regeneration from logging that occurred between 1960 and 1990, and (4) those where the overstory eucalypts were of mixed age (Table 1). None of our sites were logged over the duration of our study (i.e., between 2004

TABLE 1. Frequency distribution of the number of sites surveyed in each stand age category.

\begin{tabular}{lc}
\hline \hline Stand age & Number of sites \\
\hline Old growth & 8 \\
1939 & 60 \\
$1960-1990$ s & 9 \\
Mixed & 11 \\
\hline
\end{tabular}

Notes: Forest age was determined from field-based assessment of each site and based on the dominant age cohort of trees. On-the-ground assessments were crossed-checked against forest age-class maps created by the Government of Victoria (unpublished data), Australia. Mixed age stands were those characterized by two or more co-dominant age cohorts on a site. Old growth stands were those that dated from before 1900 . Stands of $80 \mathrm{yr}$ in age were those that regenerated after wildfires in 1939. Stands that were $\sim 30-60 \mathrm{yr}$ old were those that regenerated after disturbances between 1960 and 1990. and 2014), although there was extensive logging of the landscapes surrounding some of our sites (Fig. 1b).

\section{Bird surveys}

We conducted annual surveys from 2004 to 2014 (inclusive), with the exception of 2006 and 2008. We completed all surveys in late November, which is the breeding season for the majority of species and when summer migrants have arrived. Our standardized protocol entailed 5 min point interval counts (sensu Pyke and Recher 1983) completed at each of the 0,50 , and $100 \mathrm{~m}$ points along a central $100-\mathrm{m}$ transect at each field site. We recorded birds only when they were observed within $100 \mathrm{~m}$ of an observer. In each year of our surveys, each of our 88 field sites was surveyed by two different, experienced ornithologists, on different days to account for observer heterogeneity (Cunningham et al. 1999, Lindenmayer et al. 2009) and day effects (Field et al. 2002, Lindenmayer et al. 2009). We standardized field surveys by avoiding poor weather (rain, fog, or high winds) and completing counts between dawn and four hours after dawn. In addition, the core group of seven experienced ornithologists (with more than 10 years of training) that completed the field surveys remained largely unchanged over the duration of this study. We summarized the six point counts into a binary presence/absence measure for each species at each site.

\section{Logging variables and 2009 fire variables}

Wildfires in February 2009 burned 78,300 ha of mountain ash forest in our study region (Gibbons et al. 2012). Of our 88 field sites, 43 were unburned, with the remainder burned at either high severity ( 23 sites) or moderate severity (22 sites). Sites subject to moderateseverity fire were characterized by the ground and understory layer being killed and/or consumed but the overstory remained intact. Sites subject to high-severity fire were those in which plants in the ground, shrub, and understory layers were killed and crowns of overstory trees consumed. Initial analyses revealed no differences in bird response to fire severity and we therefore elected to complete analyses for a single combined fire severity class (i.e., burned vs. unburned).

The 2009 wildfire was the only major fire that occurred during the study period. Using spatial data (obtained from the Government of Victoria) on forest cover following the 2009 fires, we calculated a spatially weighted proportion of $20 \times 20 \mathrm{~m}$ pixels burned within a $4.5 \mathrm{~km}$ radius circle surrounding each survey site (Table 2, Appendix S1: Fig. S1). We selected this distance to reflect the maximum movement and foraging distances of the majority of (non-migratory) bird species inhabiting mountain ash forests (see Garnett et al. 2018). We employed a Gaussian kernel with parameters chosen to give weight 1 to a pixel at the center of the site and weight 0.001 to a pixel located $4.5 \mathrm{~km}$ from the site (at 1,2,3, 
TABLE 2. Descriptive statistics for the weighted proportion of the landscape surrounding our field sites $(n=88)$ that burned in 2009 or was harvested in the previous $1-5$ or $6-10$ yr of a given survey year.

\begin{tabular}{|c|c|c|c|c|c|c|}
\hline Measure and year & No. sites surveyed & Mean & Median & SD & Minimum & Maximum \\
\hline \multicolumn{7}{|l|}{ Fire } \\
\hline 2009 & 87 & 0.348 & 0.201 & 0.360 & 0 & 0.999 \\
\hline \multicolumn{7}{|l|}{ Harvesting $1-5 \mathrm{yr}$} \\
\hline 2004 & 85 & 0.013 & 0.002 & 0.022 & 0 & 0.119 \\
\hline 2005 & 87 & 0.015 & 0.003 & 0.025 & 0 & 0.127 \\
\hline 2007 & 87 & 0.018 & 0.007 & 0.025 & 0 & 0.135 \\
\hline 2009 & 87 & 0.018 & 0.010 & 0.024 & 0 & 0.119 \\
\hline 2010 & 80 & 0.023 & 0.013 & 0.027 & 0 & 0.124 \\
\hline 2011 & 86 & 0.021 & 0.009 & 0.029 & 0 & 0.140 \\
\hline 2012 & 87 & 0.022 & 0.009 & 0.028 & 0 & 0.123 \\
\hline 2013 & 83 & 0.023 & 0.014 & 0.027 & 0 & 0.117 \\
\hline 2014 & 86 & 0.020 & 0.010 & 0.025 & 0 & 0.099 \\
\hline \multicolumn{7}{|l|}{ Harvesting $6-10 \mathrm{yr}$} \\
\hline 2004 & 85 & 0.029 & 0.014 & 0.037 & 0 & 0.171 \\
\hline 2005 & 87 & 0.030 & 0.013 & 0.038 & 0 & 0.168 \\
\hline 2007 & 87 & 0.033 & 0.018 & 0.041 & 0 & 0.214 \\
\hline 2009 & 87 & 0.032 & 0.012 & 0.043 & 0 & 0.237 \\
\hline 2010 & 80 & 0.016 & 0.004 & 0.025 & 0 & 0.127 \\
\hline 2011 & 86 & 0.018 & 0.008 & 0.025 & 0 & 0.123 \\
\hline 2012 & 87 & 0.018 & 0.007 & 0.025 & 0 & 0.135 \\
\hline 2013 & 83 & 0.019 & 0.009 & 0.027 & 0 & 0.152 \\
\hline 2014 & 86 & 0.019 & 0.010 & 0.024 & 0 & 0.119 \\
\hline
\end{tabular}

and $4 \mathrm{~km}$, the weights were $0.711,0.256,0.046$, and 0.004 , respectively). We initially also compiled a site-level metric distinguishing burned $(n=45)$ from unburned $(n=43)$ sites. This metric was highly correlated with landscape-level wildfire extent (correlation $=0.68)$, and was therefore excluded from our analysis.

None of our sites were logged, but forest in the landscape surrounding our survey sites was subject to clearcutting. We calculated the spatiotemporally weighted proportion of $20 \times 20 \mathrm{~m}$ pixels logged from 1955 to a given year within a $4.5 \mathrm{~km}$ radius circle surrounding each field site for each of the survey years (2004, 2005, 2007, 2009-2014; Table 2). We summarized the variation in the spatial variables (see Appendix S1: Fig. S1) and it showed a left-skewed distribution with some sites surrounded by limited amounts of harvesting, but others with up to $40 \%$ of the surrounding area having been logged (e.g., see Fig. 1b). We included time since logging disturbance in our analysis. This variable had two categories: the amount of forest within a polygon that was logged 1-5 yr ago, and the amount of forest that was logged 6-10 yr ago. We selected these age cohorts because of the major structural differences in such stands, particularly immediate post-harvesting and then canopy closure after $\geq 6$ yr of growth.

\section{Bird life history attributes}

We extracted data on life history attributes for each bird species in our study region using compilations of bird biology and ecology published in various ornithological monographs (Garnett et al. 2018). We used $\log$ (body mass) as a proxy for size, which we analyzed as a continuous variable. We assigned each bird species to one of two categories of movement status: migrants and residents. Resident species were those that did not undertake large-scale movement such as latitudinal migration, elevational migration, or nomadic movements that typically encompass shifts exceeding hundreds to thousands of kilometers. We assigned birds to one of two broad diet categories: those that primarily consumed invertebrates and all other diet types.

\section{Statistical AnAlysis}

We analyzed patterns in detection rates representing apparent occupancy uncorrected for detectability. Apparent occupancy can informatively index species occupancy for the purpose of estimating environmental relationships in some circumstances (Hutto 2016, Marques et al. 2017). We assumed that we met these circumstances here because we assumed detectability was consistent across sites because sampling effort was constant within and between sites and across years, and because our surveys were completed largely by the same set of experienced observers under constrained survey conditions (see "Bird surveys").

We analysed the number of species detected at the site level using a Bayesian multilevel Poisson regression model. Specifically, let $d_{i t}$ represent the number of species detected at site $i$ in year $t$. Our model for mean, $\mu_{i t}$, can be expressed as follows: 


$$
d_{i t} \sim \operatorname{Poisson}\left(\mu_{i t}\right)
$$

$$
\begin{aligned}
\log \mu_{i t}= & \beta_{0}+\beta_{1} S A_{i t}^{1}+\beta_{2} S A_{i t}^{2}+\beta_{3} S A_{i t}^{3}+\beta_{4} H 15_{i t} \\
& +\beta_{6} H 610_{i t}+\beta_{7} H 610_{i t}^{2}+\beta_{8} F_{i t}+\beta_{9} F_{i t}^{2} \\
& +\beta_{10} y r_{i t}+\beta_{11} y r_{i t}^{2}+\beta_{12} F_{i t} X y r_{i t} \\
& +\beta_{13} H 15_{i t} X F_{i t}+\beta_{14} H 610_{i t} X F_{i t}+u_{i}
\end{aligned}
$$

where $S A_{i t}^{1}, S A_{i t}^{2}$ and $S A_{i t}^{3}$ are indicator variables denoting 1939, 1960-1990s, and mixed regrowth, respectively, $H 15_{i t}$ represents the amount of harvesting in the 1-5 yr prior to the survey, $H 610_{i t}$ represents the amount of harvesting in the $6-10 \mathrm{yr}$ prior to the survey, $F_{i t}$ is the amount of fire in 2009 (note this was zero in 2004, 2005, and 2007, the years prior to the 2009 wildfire) and $\mathrm{yr}_{i t}$ is the survey year. Finally, $u_{i}$ is the random effect of site, which we assumed was normally distributed with mean zero and standard deviation $\sigma_{u}$. To reduce the amount of collinearity in the covariates when implementing the quadratic effects, we employed orthogonal polynomials (standardized to have standard deviation equal 1). We express our model more compactly, using vector notation, as follows:

$$
\log \mu_{i t}=\boldsymbol{\beta}_{0}+\boldsymbol{x}_{i t}^{T} \boldsymbol{\beta}+u_{i}
$$

where $\mathbf{x}_{i t}$ is the vector of all covariates and $\boldsymbol{\beta}$ is the vector of regression parameters, excluding the intercept.

We fit the model using the brms (Bayesian regression models using stan) package (Buerkner 2017) with default priors, specifically flat priors on the elements of $\boldsymbol{\beta}$ and a one-half Student $t$ prior on $\sigma_{u}^{2}$ with zero mean, scale parameter 10 , and 3 degrees of freedom. We ran four chains for 10,000 iterations with a thinning factor of eight, discarding the first 2,000 iterations as burn-in, resulting in 4,000 samples for posterior inference. We assessed the convergence of the chains using the Gelman-Rubin statistic $(\hat{R})$ (Gelman and Rubin 1992). All model parameters had $\hat{R}$ statistics less than 1.01, indicating adequate mixing of the chains. To assess the fit of our multilevel model, we plotted residuals vs. fitted values and found no evidence to indicate departures from model assumptions (Appendix S1: Fig. S7). We present posterior medians and $95 \%$ credible intervals.

To investigate the relationship between our covariates and the apparent occurrence of individual bird species, we employed a multivariate latent variable model (described in Warton et al. 2015, Hui 2016) using the BORAL package (Hui 2016, 2018) in R (R Core Team 2018). The use of BORAL allowed us to assess the mediating effects of bird traits on the relationships between our covariates and apparent occurrence, which we explain in more detail below. A latent variable model is a regression model for multivariate data that includes latent (unobserved) predictors that allow one to model the correlation amongst species. Latent variables can also account for missing/unmeasured predictors. The values of latent variables are estimated along with the corresponding species-specific regression parameters (Warton 2015). The use of BORAL also allows for the inclusion of so-called "random row-effects," which allow one to account for design variables akin to random effects designs in generalized linear mixed models (Hui 2016).

More specifically, we modeled the multivariate species responses in the following manner. Let $y_{i t s}$ be one if species $s$ was detected on site $i$ in year $t$ and zero otherwise and let the probability of detection be $\pi_{i t s}$, which we model as follows:

$$
y_{i t s} \sim \operatorname{Bernoulli}\left(\pi_{i t s}\right) .
$$

For each species $s$, we fit the following probit regression model:

$$
\Phi^{-1}\left(\pi_{i t s}\right)=\alpha_{i}+\alpha_{i t}+\theta_{0 s}+x_{i t}^{T} \beta_{s}+\boldsymbol{z}_{i t}^{T} \theta_{s}
$$

where $\Phi$ is the cumulative distribution function for normal distribution, $\alpha_{i}$ is the random row effect for site, $\alpha_{i t}$ is the random row effect for site and time, $\theta_{0 s}$ is the species-specific intercept, the design vector $\mathbf{x}_{i t}$ is the same as defined previously, $\boldsymbol{\beta}_{s}$ is the vector of regression parameters for species $s, \boldsymbol{z}_{i t}^{T}$ is a vector of latent variables (Hui 2016) of length four, and $\boldsymbol{\theta}_{s}$ is a vector of latent variable coefficients. For additional detail on our approach to modeling, see Warton et al. (2015) and Hui (2016).

To incorporate traits into this formulation (see Warton et al. 2015, Hui 2016), let $\boldsymbol{t}_{s}$ be a vector of traits on species $s$ (in our case this is a vector of length 3 ). The mediating effect of traits was modeled by assuming that $\theta_{0 s}$ and $\boldsymbol{\beta}_{s}$ were random effects, drawn from a normal distribution as follows:

$$
\theta_{0 s} \sim N\left(\boldsymbol{t}_{s}^{\boldsymbol{T}} \mathbf{K}_{\mathbf{0}}, \sigma_{0}^{2}\right) \text { and } \beta_{s k} \sim N\left(\boldsymbol{t}_{s}^{\boldsymbol{T}} \mathbf{K}_{k}, \sigma_{k}^{2}\right)
$$

where $N\left(\mu, \sigma^{2}\right)$ is the normal distribution with mean $\mu$ and variance $\sigma^{2}$ and the $\beta_{s k}$ is the $k$ th regression coefficient in $\boldsymbol{\beta}_{s}$. The coefficients $\mathbf{K}_{\boldsymbol{k}}, k=0,1,2, \ldots$, relate the traits linearly to the regression coefficients and the $\sigma_{k}^{2}$ allow for any variation not explained by traits. We performed residual diagnostics using Dunn-Smyth residuals (Hui 2016).

We ran one Markov chain with 200,000 iterations with a burn-in of 80,000 with a thinning factor of 120 , yielding 1,000 samples for posterior inference with default priors (normal prior with zero mean and variance 10 for the fixed effects, $\boldsymbol{\beta}_{s}$, including trait coefficients, $\mathbf{K}_{\boldsymbol{k}}$, and a uniform $(0,30)$ prior for any standard deviation parameters in the model, $\sigma_{u}, \sigma_{0}, \sigma_{k}$ in the BORAL package (Hui 2016, 2018). We assessed the convergence of the chain using the Geweke diagnostic (Geweke 1992). The Geweke diagnostic is essentially a test of the means 
between two parts of the chain with the standard error calculated from the spectral density, which accounts for auto-correlation, yielding a $Z$ test for comparing the beginning and ending fractions of the Markov chain for each parameter. The Geweke diagnostic, resulted in less than $5 \%$ of the $Z$ statistics for the monitored parameters exceeding the $5 \%$ cut-off. This is consistent with the nullhypothesis-testing nature of this Geweke diagnostic (Geweke 1992). We used Dunn-Smyth residuals (Hui 2016) to assess model fit. Specifically, we plotted residuals vs. fitted values, residuals vs. both row and column index, and a normal quantile-quantile plot. There were no obvious patterns detected in any of the four residual plots (Appendix S1: Fig. S8). We present posterior medians and 95\% credible intervals for the regression parameters $\boldsymbol{\beta}_{s}$ and the trait parameters $\mathbf{K}_{\boldsymbol{k}}$ on the probit scale.

\section{RESULTS}

\section{Bird species richness}

Between 2004 and 2014, we completed 4,608 5-min point counts on our 88 sites and recorded 79 bird species (Appendix S1: Table S1). We provide descriptive statistics in Appendix S1: Table S2, Fig. S1. The model for bird species richness (see Appendix S1: Table S2) contained evidence of a quadratic relationship with fire and an interaction between the linear components of fire and year. Sites with greater amounts of fire in the surrounding landscape tended to experience larger declines in bird species richness. Bird species richness on these sites also recovered more strongly over time than sites where little of the surrounding landscape had been burned (Fig. 2). Finally, bird species richness was higher in old growth forest relative to younger-aged stands (see Appendix S1: Table S2).

\section{Relationships for individual species}

Our surveys generated sufficient data (i.e., taxa with $5 \%$ or more detections from the combined site $\times$ survey periods; $N=768$ ), to complete statistical modeling of the changes in detections of 37 individual bird species. We found a positive relationship between the probability of detection of three species and an increasing amount of forest logged 1-5 yr previously in the surrounding landscape (Appendix S1: Fig. S2) and a positive relationship between the probability of detection and the amount of forest logged 6-10 yr previously in the surrounding landscape for one species, the White-eared Honeyeater (Lichenostomus leucotis; Appendix S1: Fig. S2). Detections of the Red Wattlebird (Anthochaera carunculata) showed a negative quadratic relationship with harvesting in the prior 6-10 yr. However, no species showed evidence of quadratic relationships with logging in the preceding 1-5 yr (Appendix S1: Figs. S2, S3).

Only five of our 37 species, the Brush Cuckoo (Cacomantis variolosus), Crimson Rosella (Playcercus elegans),

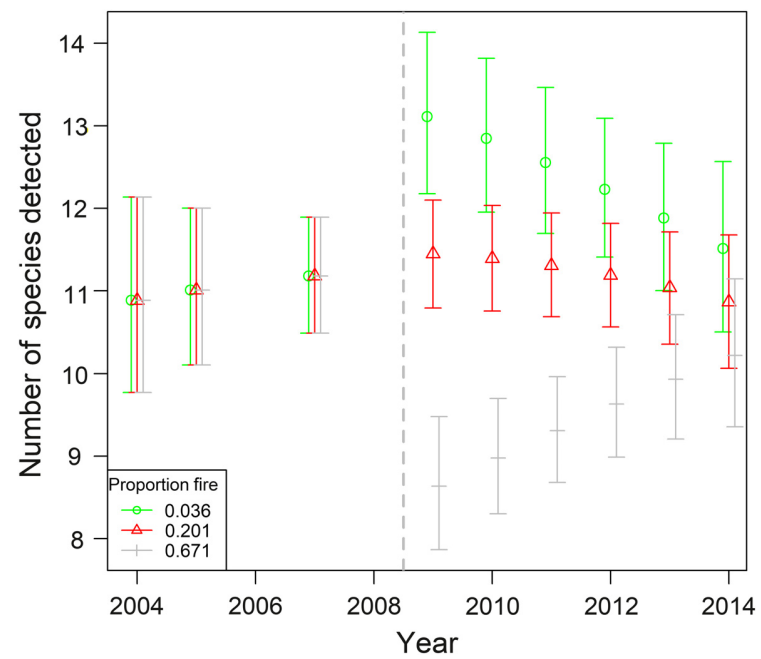

FIG. 2. Relationships between bird species richness, year, and amount of fire in the surrounding landscape. For illustrative purposes, we used the $25 \mathrm{th}, 50 \mathrm{th}$, and $75 \mathrm{th}$ percentiles of the amount of fire in the landscape, which are represented by green, red, and gray lines, respectively. The posterior medians and their $95 \%$ credible intervals are depicted for each percentile mentioned above in the corresponding year. The gray dashed vertical line indicates the timing of the 2009 wildfire in relation to when bird surveys were completed. The predictions for each stand age were averaged and the continuous covariates were held fixed at their mean values.

Gang-gang Cockatoo (Callocephalon fimbriatum), Red Wattlebird, and Striated Pardalote (Pardalotus striatus), exhibited no relationships between the probability of detection and fire, whether a linear or quadratic interaction with year, or an interaction with harvesting. Twelve species exhibited an interaction between survey year and amount of fire in the surrounding landscape (Fig. 3, Appendix S1: Fig. S4). In general, bird detections increased faster over time on sites where there was more fire in the surrounding landscape. One species, Grey Currawong (Strepera versicolor), exhibited an interaction between the amounts of harvesting and fire in the surrounding landscape (Appendix S1: Figs. S4, S6). Of the remaining species that showed evidence of relationships between fire in the surrounding landscape and probability of detection, 18 showed either negative linear relationships or quadratic relationships. Only the Flame Robin (Petroica phoenicea) showed a positive association with the amount of fire in the surrounding landscape (Appendix S1: Figs. S2, S3).

Of the species for which models contained no interaction between fire and year, we found negative relationships with year for three species: Pied Currawong (Strepera graculina), Red Wattlebird, and Superb Lyrebird (Menura novaehollandiae). There was a quadratic effect of time for one species, the Rufous Fantail (Rhipidura rufifrons).

Our analyses contained evidence of strong relationships between probability of detection and stand age, with the vast majority of species more likely to occur in 

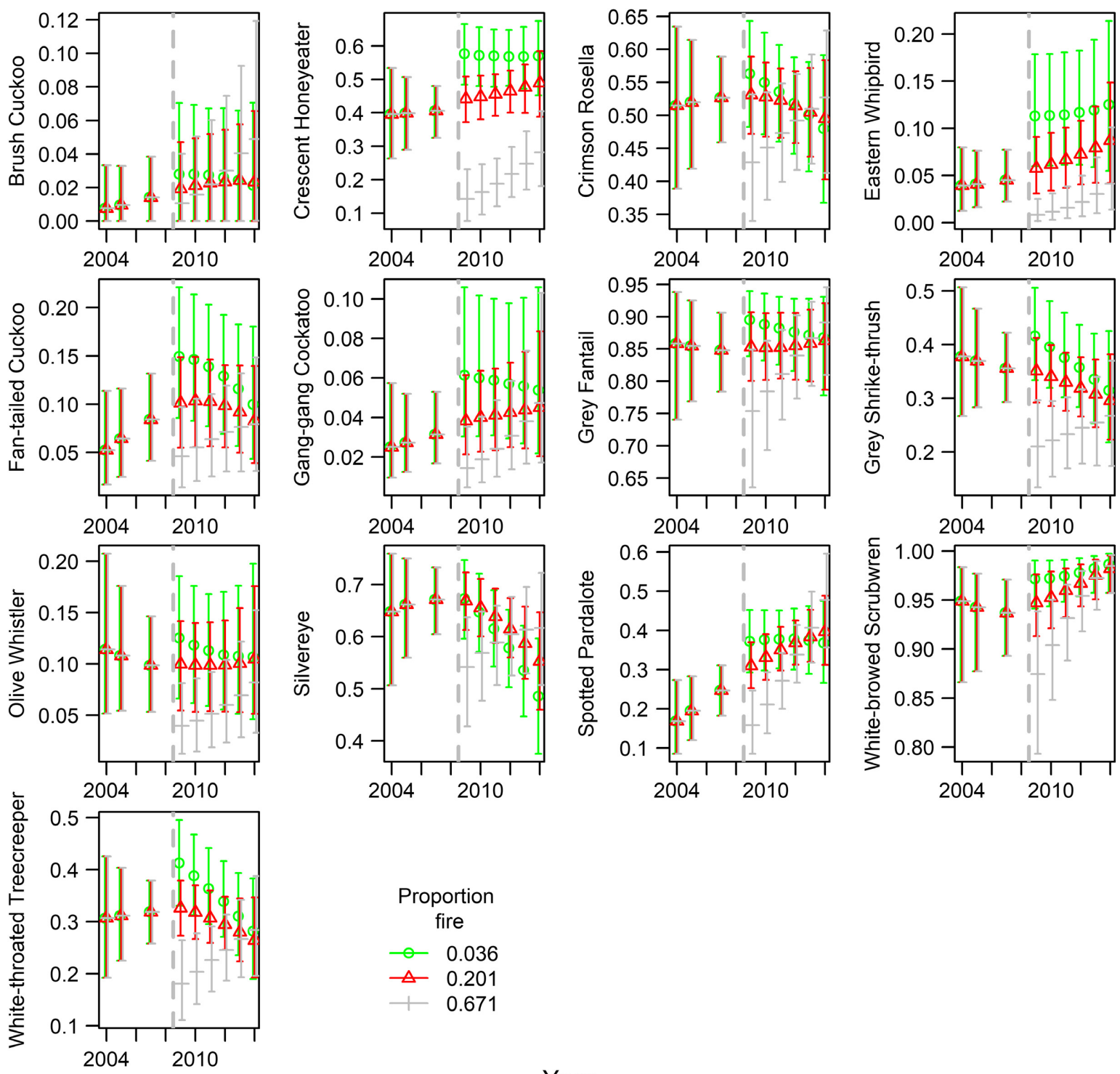

FIG. 3. Time trends in probability of detection for the 13 bird species that contained evidence of a fire $\times$ year interaction. For illustrative purposes, we used the 25th, 50th, and 75th percentiles of the amount of fire in the landscape, which are represented by green, red, and gray lines and shaded areas, respectively. The lines represent the posterior median values and the bars polygons are the $95 \%$ credible intervals. The gray dashed vertical line indicates the timing of the 2009 wildfire. Note that surveys conducted prior to 2009 were assigned zero fire in the surrounding landscape.

old growth forest (i.e., those dating from before 1900) than younger-aged stands (Appendix S1: Fig. S5). No species were more likely to occur in younger-aged forests relative to old growth forest (Appendix S1: Fig. S5).

\section{Analyses of bird life history attributes}

We found evidence of an interaction between $\log$ (body mass) and stand age, the amount of fire in the landscape in 2009, year, and fire $\times$ year (Fig. 4). There was an interaction between diet (insectivores vs. other) and stand age. Finally, there was a relationship between bird movement (migratory vs. sedentary species) and amount of fire in the landscape in 2009 (Figs. 4, 5).

\section{DisCUSSION}

We found evidence of a marked effect of fire on bird biota with detections of the vast majority of species reduced in response to an increasing amount of fire in the landscape. There was, however, evidence of recovery for some species, and primarily on sites where large amounts of the surrounding forest had been burned. Relative to fire, the effects of logging were less marked, with six 


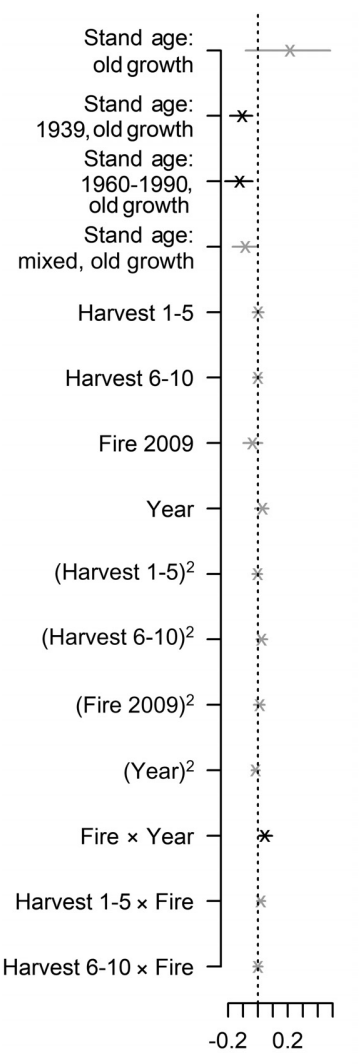

$\log$ (body mass)
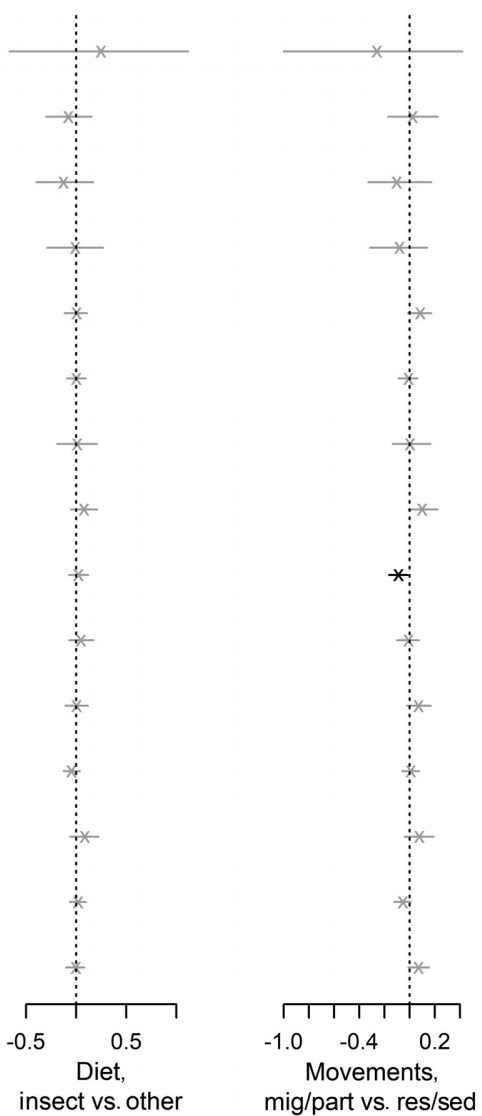

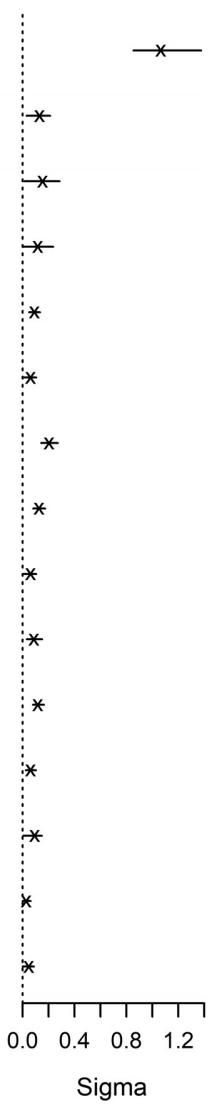

FIG. 4. Relationships between bird life history attributes (log body mass, diet, and movements) and responses to key covariates modeled. We present posterior medians and $95 \%$ credible intervals for the individual trait $\times$ covariate interaction. A gray $\mathrm{x}$ corresponds to a response that crosses zero, whereas a black $\mathrm{x}$ shows a response that does not cross zero and is important. For movement, the categories are migratory and partly migratory vs. resident/sedentary.

species responding to this covariate (on the linear and quadratic scales) and only to the amount of harvesting in the previous 1-5 yr. We found that most bird species exhibited markedly different responses to fire relative to logging. We found relationships between some bird life history attributes and the amount of fire in the landscape, year, fire $\times$ year, and stand age. We further discuss these and other key findings in the remainder of this paper.

Q1 and Q2: Relationships between the amount of logging and fire in the landscape and bird species richness and the occurrence of individual species

We uncovered strong evidence that bird species richness declined as the amount of fire around each site increased. For sites where large amounts of the surrounding forest had been burned, however, some species exhibited recovery over time. More surprising was our discovery of a positive relationship between the occurrence of several bird species at sites and the amount of forest logged in the surrounding landscape. As our survey sites were not logged (whereas 43 of 88 were burned), we suggest that these patterns could represent what we term a "concentration effect," whereby clearcut logging in the surrounding landscape removes habitat for species, triggering their movement into nearby uncut areas. That is, the unlogged areas where our surveying took place may be functioning as islands or refuges for birds. Other studies have found similar results when surrounding landscapes have been logged and birds have moved to uncut refuges (e.g., Darveau et al. 1995). This kind of response may be attributed to the relationship between resource availability in unlogged areas relative to the surrounding matrix (Estades 2001). Under these circumstances, animals may retreat from a poor quality matrix into remaining undisturbed habitat patches (resulting in a concentration effect; Driscoll et al. 2013). An earlier study of variable retention harvesting (sensu Franklin et al. 1997) in mountain ash ecosystems showed that islands of retained forest within cutblocks acted as refuges for a range of bird species (Lindenmayer et al. 2015). A postulated concentration effect is broadly consistent with another key result from our analyses showing that the vast majority of species were more likely to be detected in old growth sites (Appendix S1: Fig. S5). Historical logging and recurrent wildfire has meant that 

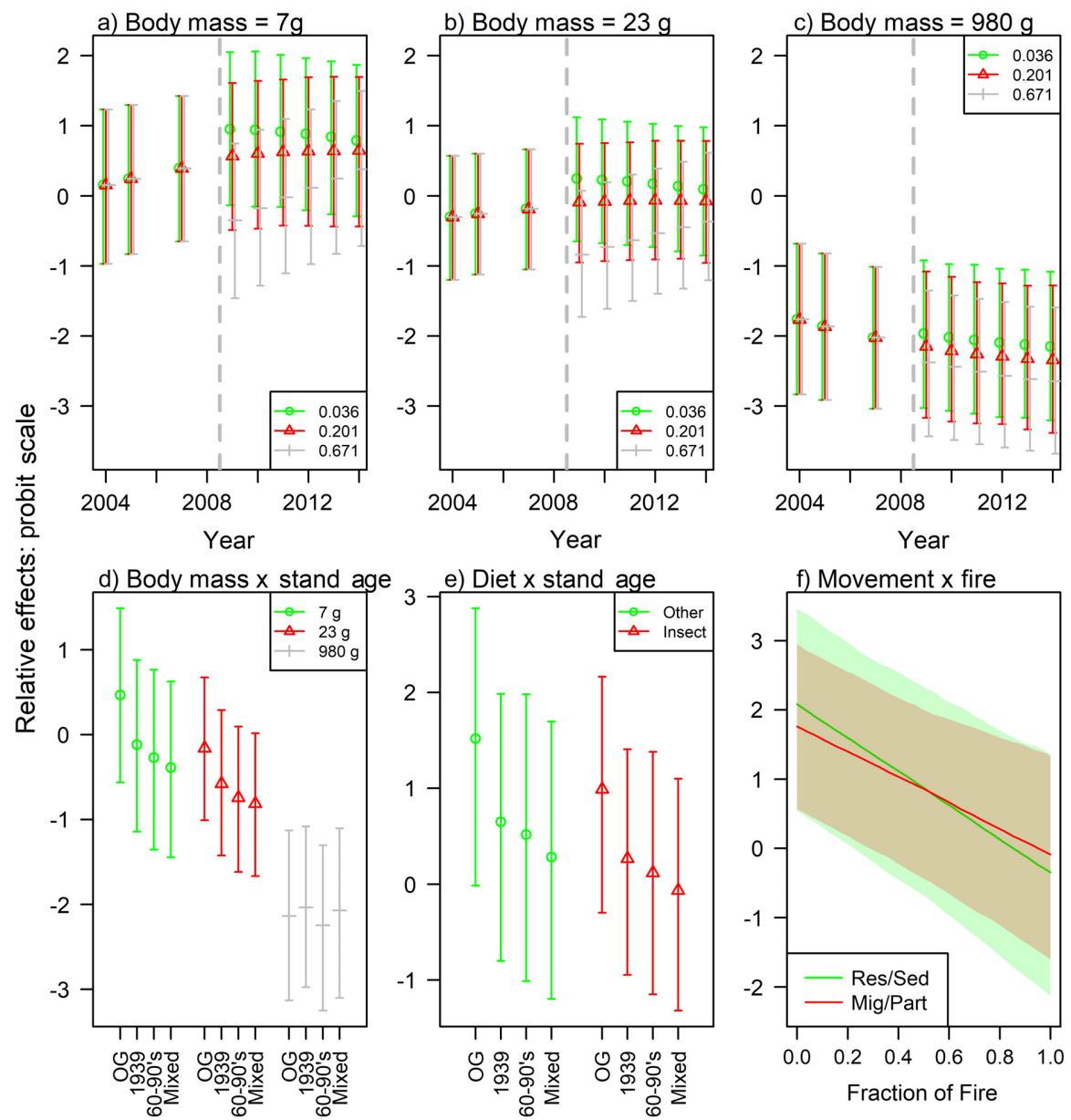

FIG. 5. Illustration of the trait by covariate interaction depicted in Fig. 4. Panels a-c show the interaction of body mass and survey year and fire interaction. We chose three values of body mass (the body mass trait was modeled on the log scale), minimum, median, and maximum, along with the varying levels of fire experienced in 2009 (for more details see Fig. 3). Panel d shows the interaction between body mass (the same three levels as panels a-c) and stand age. Panel e shows the interaction between diet (insectivore vs. others) and stand age. Panel $\mathrm{f}$ shows the interaction between movement (resident/sedentary vs. migratory and partly migratory) and the fraction of the landscape burned in 2009 . We plot posterior medians and $95 \%$ credible intervals on the probit scale holding all the other variables fixed at their mean value (continuous variables) or at their reference level (categorical variables).

old growth stands have become extremely rare in mountain ash ecosystems (now comprising $1.16 \%$ of the forest estate, relative to $30-60 \%$ historically), and are strictly protected (if they exceed 5 ha in size).

Our analyses revealed that the majority of species exhibited a negative relationship with increasing amounts of burned forest in the landscape surrounding our long-term sites (Appendix S1: Fig. S2). By contrast, the Flame Robin exhibited a positive relationship to the amount of forest burned in 2009. The Flame Robin appears to be the only bird species strongly associated with recently burned forest in mountain ash ecosystems, although it is also found in older stands where fire has been absent for $20-150+$ yr. The relative paucity of bird species associated with recently burned forest is in marked contrast to other ecosystems globally where high-severity stand-replacing fires are also a characteristic form of natural disturbance (Hutto 1995, 2008, Swanson et al. 2011). A combination of two factors may explain the relative rarity of bird species associated with recently burned mountain ash forests. First, mountain ash forests are characterized by a truncated period in which open conditions prevail following fire, with canopy closure of fast-growing regenerating forest typically occurring $3-5 \mathrm{yr}$ after perturbation. Second, the historical fire regime in mountain ash forest suggests that stand-replacing wildfires are relatively rare with the average interfire period estimated to be $107 \mathrm{yr}$ (McCarthy et al. 1999). Hence, in a broader evolutionary context, recently burned forests would have been uncommon and short lived, thereby limiting the evolution of early successional specialists.

We uncovered evidence of interactions between disturbance and time. In the case of fire $\mathrm{x}$ year interactions, 
our analyses showed that while some taxa have continued to decline following the 2009 fire, others are increasing more rapidly in landscapes where there was a large amount of fire (Fig. 3). This suggests that some species are undergoing postfire recovery as burned stands are regenerating, possibly because these populations declined markedly immediately following the fire. However, signs of recovery were not ubiquitous, with the models for 12 species not including a fire $\times$ year interaction and thereby not containing evidence of postfire recovery (Appendix S1: Fig. S4). It is possible that monitoring over much longer periods than the $10 \mathrm{yr}$ of this study will be required to uncover evidence of postfire recovery among more species.

The lack of evidence for postfire recovery for many species has major implications for forest bird conservation if fire frequency increases, as it is predicted to do in mountain ash forests as a consequence of rapid climate change (Williams et al. 2009). This is because recurrent fire may increase the number and spatial extent of areas where bird species are uncommon and elevate the risks of localized extinction. This may, in turn, have corresponding impacts on key ecological roles (e.g., pollination and seed dispersal) that bird species play in forest ecosystems (Şekercioğlu et al. 2004).

\section{Q3. Are bird responses mediated by life history attributes?}

We sought to identify relationships between the coefficients of life history attributes and spatiotemporal changes in forest cover. We found that large-bodied species were less likely to decline over time in landscapes subject to large amounts of fire in 2009. Large-bodied species have larger territory sizes than smaller species (Schoener 1968, Garnett et al. 2015). This may enable them to exploit resources over larger areas and hence be more likely to persist in extensively burned landscapes than smaller-bodied taxa (Figs. 4 and 5, Appendix S1: Table S2). We also found that migratory taxa had a positive association with landscapes subject to large amounts of fire in 2009. The greater mobility of such species may enable them to exploit forests regenerating after fire more readily than resident taxa.

A further outcome of our life history analyses was evidence that small-bodied bird species were more likely to be associated with old growth stands relative to youngeraged stands. Old growth stands are characterized by a greater range of vegetation layers (Lindenmayer et al. 2000) and hence may support more potential foraging substrates than young forest. This also may explain our findings for an association with old growth stands of birds other than insectivores.

\section{Conservation implications}

Some authors have hypothesized that in ecosystems subject to stand-replacing natural disturbances, wildfire and clearcutting will have similar impacts on biodiversity because both are high-severity perturbations (Attiwill et al. 1994, Simon et al. 2002, Van Wilgenburg and Hobson 2008). Others have argued that that because logging and fire create different spatial patterns of forest cover (McCarthy and Burgman 1995), biodiversity will exhibit markedly different responses to these kinds of disturbances (Franklin and Forman 1987, Stein et al. 2014, Phalan et al. 2019).

Our data showed that no species exhibited the same responses to fire and logging (Appendix S1: Figs. S2S5). Differences in the amount of disturbed forest created by fire vs. logging (Franklin and Forman 1987, McCarthy and Burgman 1995), as well as the speed at which they affect the landscape, may explain the marked differences in responses to these kinds of perturbations. Harvesting operations in a given cutblock gradually impact the forest over several months or more, during which birds may move from logged to uncut areas (such as our unlogged field sites). In the case of high-severity and high-intensity fire, which typically occurs over large areas within hours, birds may die en masse, thereby producing marked negative effects on the population as a whole. In the case of our study region, large parts of the area burned in the 2009 wildfires were subject to extreme fire conditions, including fire intensities of $\sim 80,000$ $\mathrm{kw} / \mathrm{m}^{2}$, flame heights exceeding $60 \mathrm{~m}$, and wind speeds exceeding $100 \mathrm{~km} / \mathrm{h}$. Notably, several other studies have quantified very high levels of mortality of animals as a direct result of fire (Brynard 1971, Fox 1978, Whelan 1995, Keith et al. 2002). Moreover, we found no evidence of increased detections of birds in unburned areas following the 2009 fires. Thus, the large and abrupt changes in forest cover that extend over large areas as a result of wildfire (Turner et al. 2003) likely underpin more marked effects of fire relative to the incremental and often spatially dispersed effects of logging ( $\mathrm{Li}$ et al. 1993). Although up to $40 \%$ of the surrounding landscape within a $4.5 \mathrm{~km}$ radius was cutover in some landscapes (Fig. 1; see also Appendix S1: Fig. S1), on average the amount of burned forest surrounding our sites was far higher $(20 \%)$ than the amount of forest that was logged (3-6\%) (Appendix S1: Table S2). This also may explain the stronger responses to fire than logging that characterized our study.

Despite differences in the extent and frequency in the amount of fire and logging in the landscape and associated effects on birds, both kinds of stand-replacing disturbance have a similar negative impact on the amount of old growth forest. This is an important similarity given that one of the key outcomes of our work was the strong positive effects of stand age and the number of bird species detected. Detections of the vast majority of individual taxa also were markedly higher in old growth stands than in younger-aged forest (Fig. 4). Old growth forests are characterized by greater stand structural complexity than younger forests (Lindenmayer et al. 2000) and subsequently may provide habitat for a broader range of bird species. A key concern is that old growth 
stands of mountain ash forests are now extremely rare in the Central Highlands of Victoria. Only 1.16\% of this forest ecosystem is old growth, although it used to comprise $30-60 \%$ of the forest estate prior to European settlement (Lindenmayer and McCarthy 2002). Given the importance of old growth forests for bird and other biodiversity, areas of old growth forest need to be expanded substantially through strategic reservation of existing younger-aged stands that are allowed to grow through to ecological maturity (Taylor et al. 2017).

Our analyses suggest that uncut stands may act as refuges from human disturbance and therefore have an important role in supporting populations of forest birds when the surrounding forest is logged. Forest managers may therefore need to carefully consider how much of a given landscape is subject to harvesting, especially if large areas of the same landscape have also been subject to fire (which is the case in many parts of the mountain ash estate).

We focused on the effects on forest birds of the amount of logged and burned forest surrounding our array of long-term field sites. We did not explore potential interacting landscape effects of fire and logging such as where areas subject to a major conflagration are subject to postfire salvage logging. Salvage logging operations are spatially limited in mountain ash forests and demand fit-for-purpose experiments (see Lindenmayer et al. 2018c). Nevertheless, further work is required to quantify other interacting effects of logging and fire on biodiversity at the landscape level, especially as a past history of harvesting can elevate the risk of subsequent higher severity fires (Taylor et al. 2014, Zylstra 2018), as also found in a range of forest types globally (Thompson et al. 2007, Cochrane and Laurance 2008).

\section{Concluding comments}

Our analyses revealed that birds exhibit complex, time-dependent, and species-specific responses to fire and logging. Both kinds of disturbances are high-severity perturbations, but our results suggests that responses at a landscape-scale to one kind of disturbance may not be readily predictable based on an understanding of the responses to another kind of (albeit superficially similar) disturbance. Our findings also highlight the challenges associated with understanding how spatiotemporal changes in forest cover arising from different kinds of disturbances can influence multispecies assemblages such as those that characterize the bird communities in many disturbance-prone ecosystems globally.

\section{ACKNOWLEDGMENTS}

This project has received funding from the Australian Government (National Environmental Science Program) and the Victorian Government (Parks Victoria, and Department of Environment, Land, Water and Planning). Expert assistance in bird data collection was provided by Mason Crane, Damian Michael, Chris MacGregor, Dave Smith, Clare Crane, Thea
O'Loughlin, and Sachiko Okada. Tabitha Boyer assisted in manuscript preparation. We thank Francis Hui for discussions about the application of his statistical package BORAL. Comments from three anonymous referees greatly improved an earlier version of the manuscript.

\section{Literature Cited}

Ashton, D. H. 1981. Fire in tall open forests (wet sclerophyll forests). Pages 339-366 in A. M. Gill, R. H. Groves, and I. R. Noble, editors. Fire and the Australian biota. Australian Academy of Science, Canberra, Australian Capital Territory, Australia.

Attiwill, P. M., R. Florence, W. E. Hurditch, and W. J. Hurditch. 1994. The burning continent. Forest ecosystems and fire management in Australia. Institute of Public Affairs, Melbourne, Victoria, Australia.

Barlein, F. 2016. Migratory birds under threat. Science 354:547-548.

Barton, P. S., C. F. Sato, G. M. Kay, D. Florance, and D. B. Lindenmayer. 2016. Effects of environmental variation and livestock grazing on ant community structure in temperate eucalypt woodland. Insect Conservation and Diversity 9:124 134.

Bergeron, Y., et al. 2006. Past, current, and future fire frequencies in Quebec's commercial forests: implications for the cumulative effects of harvesting and fire on age-class structure and natural disturbance-based management. Canadian Journal of Forest Research 36:2737-2744.

Blair, D., L. McBurney, B. W. S. Banks, and D. B. Lindenmayer. 2016. Disturbance gradient shows logging affects plant functional groups more than fire. Ecological Applications 26:2280-2301.

Both, B., C. A. van Turnhout, R. G. Bijlsma, H. Siepel, A. J. van Strein, and R. P. Foppen. 2010. Avian population consequences of climate change are most severe for long-distance migrants in seasonal habitats. Proceedings of the Royal Society B 277:1259-1266.

Bowd, E. J., D. B. Lindenmayer, S. C. Banks, and D. P. Blair. 2018. Logging and fire regimes alter plant communities. Ecological Applications 28:826-841.

Bowd, E. J., S. C. Banks, C. L. Strong, and D. B. Lindenmayer. 2019. Long-term impacts of wildfire and logging on forest soils. Nature Geoscience 12:113-118.

Brynard, A. M. 1971. Controlled burning in the Kruger National Park: history and development of a veld burning policy. Pages 219-231 in E. V. Komarek, editor. Proceedings of the 11th Annual Tall Timbers Fire Ecology Conference. Tall Timbers Research Station, Tallahassee, Florida, USA.

Buerkner, P.-C. 2017. brms: An R Package for Bayesian Multilevel Models using Stan. Journal of Statistical Software 80:1-28.

Calder, W. A. 1984. Size, function and life history. Harvard University Press, Cambridge, Massachusetts, USA.

Clarke, M. F. 2008. Catering for the needs of fauna in fire management: science or just wishful thinking? Wildlife Research 35:385-394.

Clavero, M., L. Brotons, and S. Herrando. 2011. Bird community specialization, bird conservation and disturbance: the role of wildfires. Journal of Applied Ecology 43:128-136.

Cochrane, M. A., and W. F. Laurance. 2008. Synergisms among fire, land use, and climate change in the Amazon. Ambio 37:522-527.

Cunningham, R. B., D. B. Lindenmayer, H. A. Nix, and B. D. Lindenmayer. 1999. Quantifying observer heterogeneity in bird counts. Australian Journal of Ecology 24:270-277. 
Darveau, M., P. Beauchesne, L. Belanger, J. Hout, and P. Larue. 1995. Riparian forest strips as habitat for breeding birds in boreal forest. Journal of Wildlife Management 59:67-78.

Driscoll, D. A., et al. 2010. Fire management for biodiversity conservation: key research questions and our capacity to answer them. Biological Conservation 143:1928-1939.

Driscoll, D. A., S. C. Banks, P. S. Barton, D. B. Lindenmayer, and A. L. Smith. 2013. Conceptual domain of the matrix in fragmented landscapes. Trends in Ecology \& Evolution 28:605-613.

Estades, C. F. 2001. The effect of breeding-habitat patch size on bird population density. Landscape Ecology 16:161-173.

Farnsworth, L. M., D. G. Nimmo, L. T. Kelly, A. F. Bennett, and M. F. Clarke. 2014. Does pyrodiversity beget alpha, beta or gamma diversity? A case study using reptiles from semiarid Australia. Diversity and Distributions 20:663-673.

Fedrowitz, K. F., et al. 2014. Can retention forestry help conserve biodiversity? A meta-analysis. Journal of Applied Ecology 51:1669-1679.

Field, S. A., A. J. Tyre, and H. P. Possingham. 2002. Estimating bird species richness: how should repeat surveys be organized in time? Austral Ecology 27:624-629.

Fox, A. M. 1978. The '72 fire of Nadgee Nature Reserve. Parks and Wildlife 2:5-24

Franklin, J. F., and R. T. Forman. 1987. Creating landscape patterns by forest cutting: ecological consequences and principles. Landscape Ecology 1:5-18.

Franklin, J. F., D. E. Berg, D. A. Thornburgh, and J. C. Tappeiner. 1997. Alternative silvicultural approaches to timber harvest: variable retention harvest systems. Pages 111-139 in K. A. Kohm and J. F. Franklin, editors. Creating a forestry for the 21st century. Island Press, Covelo, California, USA.

Frelich, L. E. 2005. Forest dynamics and disturbance regimes. Studies from temperate evergreen-deciduous forests. Cambridge University Press, Cambridge, UK.

Garnett, S. T., et al. 2015. Biological, ecological, conservation and legal information for all species and subspecies of Australian bird. Scientific Data 2:150061.

Garnett, S., P. Latch, D. B. Lindenmayer, and J. Woinarski. 2018. Recovering australian threatened species. CSIRO Publishing, Melbourne, Australia, A book of hope.

Gelman, A., and D. B. Rubin. 1992. Inference from iterative simulation using multiple sequences. Statistical Science $7: 457-511$.

Geweke, J. 1992. Evaluating the accuracy of sampling-based approaches to the calculation of posterior moments. Pages 169-193 in J. M. Bernado, J. O. Berger, A. P. Dawid, and A. F. M. Smith, editors. Bayesian statistics 4. Clarendon Press, Oxford, UK.

Gibb, H., and S. A. Cunningham. 2010. Revegetation of farmland restores function and composition of epigaeic beetle assemblages. Biological Conservation 143:677-687.

Gibbons, P., et al. 2012. Land management practices associated with house loss in wildfires. PLoS ONE 7:e29212.

Gilroy, J. J., J. A. Gill, S. H. Butchart, V. R. Jones, and A. M. Franco. 2016. Migratory diversity predicts population declines in birds. Ecology Letters 19:308-317.

Guillemete, M., A. J. Woakes, J. Larochelle, E. T. Polymeropoulos, J.-M. Granbois, P. J. Butler, D. Pelletier, P. B. Frappell, and S. J. Portuga. 2016. Does hyperthermia constrain flight duration in a short-distance migrant? Philosophical Transactions of the Royal Society B 371:20150386.

Haddad, N. M., et al. 2015. Habitat fragmentation and its lasting impact on Earth's ecosystem. Science Advances 1:e1500052.

Hart, S., and H. Y. Chen. 2008. Fire, logging, and overstory affect understory abundance, diversity and composition in boreal forest. Ecological Monographs 78:123-140.
Hui, F. K. C. 2016. BORAL: Bayesian ordination and regression analysis of multivariate abundance data. R. Methods in Ecology and Evolution 7:744-750.

Hui, F. K. C. 2018. BORAL: Bayesian ordination and regression analysis. $\mathrm{R}$ package version 1.7. https://cran.r-project. org/web/packages/boral/boral.pdf

Hutto, R. L. 1995. Composition of bird communities following stand-replacement fires in northern Rocky Mountain (USA) conifer forests. Conservation Biology 10:1041-1058.

Hutto, R. 2008. The ecological importance of severe wildfires: some like it hot. Ecological Applications 18:1827-1834.

Hutto, R. 2016. Should scientists be required to use a modelbased solution to adjust for possible distance-based detectability bias? Ecological Applications 26:1287-1294.

Inger, R., R. Gregory, J. P. Duffy, I. Stott, P. Vorisek, and K. J. Gaston. 2014. Common European birds are declining rapidly while less abundant species' numbers are rising. Ecology Letters 18:28-36.

Keith, D., J. Williams, and J. Woinarski. 2002. Fire management and biodiversity conservation: key approaches and principles. Pages 401-425 in R. Bradstock, J. Williams, and A. M. Gill, editors. Flammable Australia. The fire regimes and biodiversity of a continent. Cambridge University Press, Cambridge, UK.

Kelly, L. T., L. Brotons, and M. A. McCarthy. 2016. Putting pyrodiversity to work for animal conservation. Conservation Biology 31:952-955.

Kodandapani, N., M. A. Cochrane, and R. Sukumar. 2004. Conservation threat of increasing fire frequencies in the Western Ghats, India. Conservation Biology 18:1553-1561.

Kotliar, N. B., P. L. Kennedy, and K. Ferree. 2007. Avifaunal responses to fire in southwestern montane forests along a burn severity gradient. Ecological Applications 17:491-507.

Li, H., J. F. Franklin, F. J. Swanson, and T. A. Spies. 1993. Developing alternative forest cutting patterns: a simulation approach. Landscape Ecology 8:63-75.

Lindenmayer, D. B. 2009. Forest pattern and ecological process: a synthesis of 25 years of research. CSIRO Publishing, Melbourne, Victoria, USA.

Lindenmayer, D. B. 2016. Interactions between forest resource management and landscape structure. Current Landscape Ecology Reports 1:10-18.

Lindenmayer, D. B., and J. F. Franklin. 2002. Conserving forest biodiversity: a comprehensive multiscaled approach. Island Press, Washington, D.C., USA.

Lindenmayer, D. B., and M. A. McCarthy. 2002. Congruence between natural and human forest disturbance: a case study from Australian montane ash forests. Forest Ecology and Management 155:319-335.

Lindenmayer, D. B., R. B. Cunningham, C. F. Donnelly, and J. F. Franklin. 2000. Structural features of old growth Australian montane ash forests. Forest Ecology and Management 134:189-204.

Lindenmayer, D. B., J. T. Wood, and C. MacGregor. 2009. Do observer differences in bird detection affect inferences from large-scale ecological studies? Emu 109:100-106.

Lindenmayer, D. B., W. Blanchard, L. McBurney, D. Blair, S. C. Banks, D. A. Driscoll, A. Smith, and A. M. Gill. 2014. Complex responses of birds to landscape-level fire extent, fire severity and environmental drivers. Diversity and Distributions 20:467-477.

Lindenmayer, D. B., W. Blanchard, P. Tennant, P. Barton, K. Ikin, A. Mortelliti, S. Okada, M. Crane, and D. Michael. 2015. Richness is not all: how changes in avian functional diversity reflect major landscape modification caused by pine plantations. Diversity and Distributions 21:836-847.

Lindenmayer, D. B., W. Blanchard, D. Blair, L. McBurney, and S. C. Banks. 2016. Environmental and human drivers of large 
old tree abundance in Australian wet forests. Forest Ecology and Management 372:226-235.

Lindenmayer, D. B., et al. 2018a. Weather effects on birds of different size are mediated by long-term climate and vegetation type in endangered temperate woodlands. Global Change Biology 25:675-685.

Lindenmayer, D. B., et al. 2018b. Tests of predictions associated with temporal changes in Australian bird populations. Biological Conservation 222:212-221.

Lindenmayer, D. B., L. McBurney, D. Blair, J. Wood, and S. C. Banks. 2018c. From unburnt to salvage logged: quantifying bird responses to different levels of disturbance severity. Journal of Applied Ecology 55:1626-1636.

Lindenmayer, D. B., et al. 2019. Do migratory and resident birds differ in their responses to interacting effects of climate, weather and vegetation? Diversity and Distributions 25:449461.

Lomolino, M. V., and D. R. Perault. 2007. Body size variation in mammals in a fragmented, temperate rainforest. Conservation Biology 21:1059-1069.

Lutze, M. T., R. G. Campbell, and P. C. Fagg. 1999. Development of silviculture in the native State forests of Victoria. Australian Forestry 62:236-244.

Maravalhas, J., and H. L. Vasconcelos. 2014. Revisiting the pyrodiversity-biodiversity hypothesis: long-term fire regimes and the structure of ant communities in a Neotropical savanna hotspot. Journal of Applied Ecology 51:1661-1668.

Marques, T. A., et al. 2017. Model-based approaches to deal with detectability: a comment on Hutto. Ecological Applications 27:1694-1698.

McCarthy, M. A., and M. A. Burgman. 1995. Coping with uncertainty in forest wildlife planning. Forest Ecology and Management 74:23-36.

McCarthy, M. A., A. M. Gill, and D. B. Lindenmayer. 1999. Fire regimes in mountain ash forest: evidence from forest age structure, extinction models and wildlife habitat. Forest Ecology and Management 124:193-203.

Mouillot, D., N. A. Graham, S. Villeger, N. W. Mason, and D. R. Bellwood. 2012. A functional approach reveals community responses to disturbances. Trends in Ecology \& Evolution 28:167-177.

Nimmo, D. G., L. T. Kelly, L. M. Spence-Bailey, S. J. Watson, R. S. Taylor, M. F. Clarke, and A. F. Bennett. 2013. Fire mosaics and reptile conservation in a fire-prone region. Conservation Biology 27:345-353.

Phalan, B., J. M. Northrup, Z. Yang, R. L. Deal, J. Rousseau, T. A. Soies, and M. G. Betts. 2019. Impacts of the Northwest Forest Plan on forest composition and bird populations. Proceedings of the National Academy of Sciences USA 116:3322-3327.

Pons, P., and M. Clavero. 2010. Bird responses to fire severity and time since fire in managed mountain rangelands. Animal Conservation 13:294-305.

Powney, G. D., C. Carvell, M. Edwards, R. K. Morris, H. E. Roy, B. A. Woodcock, and N. Isaac. 2019. Widespread losses of pollinating insects in Britain. Nature Communications 10:1018.

Pulsford, S. 2012. What's left behind? The impact of biological legacies on beetle populations after fire? Honours Thesis. The Australian National University, Canberra, Australia.

Pulsford, S., D. Driscoll, and D. B. Lindenmayer. 2016. A succession of theories: a framework to purge redundancy in post-disturbance theory. Biological Reviews 91:148-167.

Pyke, G. H., and H. F. Recher. 1983. Censusing Australian birds: a summary of procedures and a scheme for standardisation of data presentation and storage. Pages 55-63 in S. J.
Davies, editor. Methods of censusing birds in Australia. Proceedings of a symposium organised by the Zoology section of the ANZAAS and the Western Australian Group of the Royal Australasian Ornithologists Union. Department of Conservation and Environment, Perth, Western Australia, Australia.

R Core Team. 2018. R: A language and environment for statistical computing. R Foundation for Statistical Computing, Vienna, Austria.

Ritchie, M. 2010. Scale, heterogeneity and the structure and diversity of ecological communities. Princeton University Press, Princeton, New Jersey, USA.

Runge, C., J. E. Watson, S. H. Butchart, J. O. Hanson, H. P. Possingham, and R. A. Fuller. 2015. Protected areas and global conservation of migratory birds. Science 350:1255-1258.

Sanderson, F. J., P. F. Donald, D. J. Pain, I. J. Burfield, and F. P. J. van Bommel. 2006. Long-term population declines in AfroPaleartic migrant birds. Biological Conservation 131:93-105.

Schmidt-Nielsen, K. 1984. Scaling: why is animal size so important?. Cambridge University Press, Cambridge, UK.

Schoener, T. W. 1968. Sizes of feeding territories among birds. Ecology 49:123-141.

Seidl, R., K. Albrich, D. Thom, and W. Rammer. 2018. Harnessing landscape heterogeneity for managing future disturbance risks in forest ecosystems. Journal of Environmental Management 209:46-56.

Şekercioğlu, C. H., G. C. Daily, and P. R. Ehrlich. 2004. Ecosystem consequences of bird declines. Proceedings of the National Academy of Sciences USA 101:18042-18047.

Simon, N. P., F. E. Schwab, and R. D. Otto. 2002. Songbird abundance in clearcut and burned stands: a comparison of natural disturbance and forest management. Canadian Journal of Forest Research 32:1343-1350.

Sitters, H., F. J. Christie, J. Di Stefano, M. Swan, T. Penman, P. C. Collins, and A. York. 2014. Avian responses to the diversity and configuration of fire age classes and vegetation types across a rainfall gradient. Forest Ecology and Management 318:13-20.

Sitters, H., J. Di Stefano, F. J. Christie, M. Swan, and A. York. 2016. Bird functional diversity decreases with time since disturbance: Does patchy prescribed fire enhance ecosystem function? Ecological Applications 26:115-127.

Slik, J. W. F., R. W. Verburg, and P. Kebler. 2002. Effects of fire and selective logging on the tree species composition of lowland dipterocarp forest in East Kalimantan, Indonesia. Biodiversity and Conservation 11:85-98.

Smith, A. L., D. Blair, L. McBurney, S. C. Banks, P. S. Barton, W. Blanchard, D. A. Driscoll, A. M. Gill, and D. B. Lindenmayer. 2013. Dominant drivers of seedling establishment in a fire-dependent obligate seeder: climate or fire regimes? Ecosystems 17:258-270.

Spies, T. A., K. N. Johnson, K. M. Burnett, J. L. Ohmann, B. C. McComb, G. H. Reeves, P. Bettinger, J. D. Kline, and B. Garber-Yonts. 2007. Cumulative ecological and socioeconomic effects of forest policies in Coastal Oregon. Ecological Applications 17:5-17.

Stein, A., K. Gerstner, and H. Kreft. 2014. Environmental heterogeneity as a universal driver of species richness across taxa, biomes and spatial scales. Ecology Letters 17:866880 .

Swanson, M. E., J. F. Franklin, R. L. Beschta, C. M. Crisafulli, D. A. DellaSala, R. L. Hutto, D. B. Lindenmayer, and F. J. Swanson. 2011. The forgotten stage of forest succession: early-successional ecosystems on forest sites. Frontiers in Ecology and the Environment 9:117-125.

Taylor, C., M. A. McCarthy, and D. B. Lindenmayer. 2014. Non-linear effects of stand age on fire severity. Conservation Letters 7:355-370. 
Taylor, C., N. Cadenhead, D. B. Lindenmayer, and B. A. Wintle. 2017. Improving the design of a conservation reserve for a critically endangered species. PLoS ONE 12:e0169629.

Thom, D., and R. Seidl. 2016. Natural disturbance impacts on ecosystem services and biodiversity in temperate and boreal forests. Biological Reviews 91:760-781.

Thompson, J. R., T. A. Spies, and L. M. Ganio. 2007. Reburn severity in managed and unmanaged vegetation in a large wildfire. Proceedings of the National Academy of Sciences USA 104:10743-10748.

Tilman, D., M. Clark, D. R. Williams, K. Kimmel, S. Polasky, and C. Packer. 2017. Future threats to biodiversity and pathways to their prevention. Nature 546:73-81.

Todd, C. R., D. B. Lindenmayer, K. Stamation, S. AcevedoCatteneo, S. Smith, and L. F. Lumsden. 2016. Assessing reserve effectiveness: application to a threatened species in a dynamic fire prone forest landscape. Ecological Modelling 338:90-100.

Turner, M. G., W. H. Romme, and D. B. Tinker. 2003. Surprises and lessons from the 1988 Yellowstone fires. Frontiers in Ecology and the Environment 1:351-358.

Tylianakis, J. M., R. Didham, J. Bascompte, and D. A. Wardle. 2008. Global change and species interactions in terrestrial ecosystems. Ecology Letters 11:1351-1363.
Van Wilgenburg, S. L., and K. A. Hobson. 2008. Landscapescale disturbance and boreal forest birds: can large single-pass harvest approximate fires? Forest Ecology and Management 256:136-146.

Warton, D. 2015. New opportunities at the interface between ecology and statistics. Methods in Ecology and Evolution 6:363-365.

Warton, D. I., F. G. Blanchet, R. B. O'Hara, O. Ovaskainen, S. Taskinen, S. C. Walker, and F. K. C. Hui. 2015. So many variables: joint modeling in community ecology. Trends in Ecology \& Evolution 30:776-779.

Watson, S. J., G. W. Luck, P. G. Spooner, and D. M. Watson. 2014. Land-use change: incorporating the frequency, sequence, time span, and magnitude of changes into ecological research. Frontiers in Ecology and the Environment 12:241-249.

Whelan, R. J. 1995. The ecology of fire. Cambridge University Press, Cambridge, UK.

Williams, R. J., et al. 2009. Interactions between climate change, fire regimes and biodiversity in Australia. A preliminary assessment. Department of Climate Change and Department of the Environment, Water, Heritage and the Arts, Canberra, Australian Capital Territory, Australia.

Zylstra, P. 2018. Flammability dynamics in the Australian Alps. Austral Ecology 43:578-591.

SUPPORTING INFORMATION

Additional supporting information may be found online at: http://onlinelibrary.wiley.com/doi/10.1002/eap.1999/full

Data Availability

Data are availability from the Dryad Digital Repository: https://doi.org/10.5061/dryad.4c44hq3 